\title{
ANÁLISE SINTÉTICA DAS ALTERAÇÕES LEGISLATIVAS ACERCA DO DIREITO REAL DE HABITAÇÃO
}

\section{ARTIGO ORIGINAL}

FERREIRA, Bruna de Fátima Tavares Targino ${ }^{1}$

FERREIRA, Bruna de Fátima Tavares Targino. Análise sintética das alterações legislativas acerca do Direito Real De Habitação. Revista Científica Multidisciplinar Núcleo do Conhecimento. Ano 05, Ed. 04, Vol. 02, pp. 122-130. Abril de 2020. ISSN: 2448-0959, Link de acesso: https://www.nucleodoconhecimento.com.br/lei/direitoreal-de-habitacao

\section{RESUMO}

O estudo do tema selecionado denota toda a complexidade que envolve os diversos institutos tratados pelo livro do direito de família dentro de nossa codificação civil, razão pela qual o direito real de habitação, dentre muitos outros, merece destaque. $\mathrm{A}$ proposta deste artigo é delinear a melhor definição do tema, perpassando pelas modificações legislativas decorrentes da evolução experimentada pela sociedade para, por fim, pontuar questionamentos acerca do emprego do Codex superado ou do vigente em consonância com as disposições transitórias e a ultratividade legal acerca, por exemplo, do denominado "estado de viuvez" entendido como condição resolutiva do direito real de habitação, em consonância com a interpretação de artigo do Diploma de 1916. A utilização de trechos selecionados da melhor doutrina obtidos através de árdua pesquisa e a leitura da jurisprudência pátria se encarregarão de direcionar os apontamentos e críticas suscitadas perante hipóteses casuísticas que serão imprescindíveis à compreensão do tema. Sendo certo que, uma vez observados os muitos meandros que envolvem a matéria eleita como plano de fundo deste trabalho, indubitavelmente, restará evidente a ultimação da atividade constante, eficaz e

\footnotetext{
${ }^{1}$ Pós-graduanda em Direito Privado na UCAM, Graduada em Direito - FACHA.
} 
afinada do Legislativo que deve atuar como instrumento balizador do almejado equilíbrio de direitos entre as partes.

Palavras-chave: Direito Real de Habitação, equilíbrio de direitos, ultratividade legal, estado de viuvez.

\section{INTRODUÇÃO}

Há muito se repete no tocante ao estudo do direito, que este se divide em duas grandes áreas denominadas: Direito Público e Direito Privado. Decerto, ainda que não haja consenso entre os Juristas, tal dicotomia é amplamente estudada e utilizada para auxiliar a distribuição dos temas.

Quando nos debruçamos sobre a imensidão do Direito Privado, indubitavelmente deparamo-nos com o Direito Civil, ramo do direito privado de enorme importância e que tem a função de reger as relações entre os particulares.

O conceito de Direito Civil, pode ser observado por diversos vieses, no entanto, a roupagem simples do professor Carlos Roberto[2] parece-nos das mais adequadas, uma vez que classifica este ramo do direito privado como um direito comum incumbido de dar disciplina as questões inerentes a vida das pessoas e àquelas referentes as relações entre particulares.

Nesta esteira, faz-se possível afirmar que o Direito Civil é o ramo do Direito Privado que acompanhará boa parte de nossas relações - de antes de nascermos até o final de nossas vidas, dividindo-se em duas partes: Geral e Especial, as quais serão repartidas em livros.

Diante destas classificações e das inúmeras matérias tratadas pelo Codex Civil, o livro que cuida dos direitos de Família desperta bastante interesse. A uma pela proximidade com a realidade, cotidiano de cada um e a duas pelas muitas transformações legais impingidas pelas mudanças sofridas pela sociedade. 
Partindo deste raciocínio, mergulhamos neste trabalho imbuídos do desejo de trazer a lume os pontos mais controvertidos do denominado Direito Real de Habitação. Tema que sofreu mudanças com a chegada do Novo Código Civil de 2002, mas que devido a ultratividade da lei, ainda causa confusão quando o caso concreto requer a aplicação da Lei anterior (CC/1916).

Ao longo deste artigo abordaremos o que é o Direito Real de Habitação e discorreremos sobre questões que circundam o tema: Quem faz jus ao direito? Qual a duração do exercício deste direito? O regime matrimonial interfere?

Objetiva-se ao término deste estudo ter todas as questões inerentes à matéria elucidadas, perpassando pela Jurisprudência pátria e esclarecendo as possíveis controvérsias quanto a aplicação de lei no tempo, fazendo-se uso de exemplos e/ou casos concretos para melhor entendimento do tema.

\section{CONCEITUAÇÃO SINTÉTICA}

O denominado "Direito Real De Habitação" encontra-se previsto no artigo 1831 do Código Civil[3] consubstanciando o direito que o cônjuge supérstite possui de permanecer no imóvel destinado a residência da família, qualquer que seja o regime de bens, desde que seja o único bem daquela natureza a inventariar.

Partindo do conceito acima já é possível apontar modificações legislativas posto que no art. 1611, §2º , do Código Civil/1916[4] o legislador impunha o regime de comunhão universal de bens e, ainda, que o cônjuge sobrevivente mantivesse o estado de viuvez.

Não há dúvidas quanto à ampliação das benesses do novo diploma legal que não mais se restringe ao regime de comunhão universal de bens. A polêmica ficou por conta da retirada de parte do texto legal que previa a obrigação da mantença do "estado de viuvez", vejamos:

Art. 1.611, § 2,$(\mathrm{CC} / 1916)$ : "Ao cônjuge sobrevivente, casado sob regime de comunhão universal, enquanto viver e permanecer viúvo, será assegurado, sem prejuízo da participação que lhe caiba na herança, o 
direito real de habitação relativamente ao imóvel destinado à residência da família, desde que seja o único bem daquela natureza a inventariar."

Questão essa já pacificada pela Doutrina que entende, majoritariamente, que houve um silêncio eloquente do legislador acerca da manutenção do "estado de viuvez", neste sentido, colacionamos a brilhante comparação dos Doutrinadores Cristiano Chaves de Farias e Nelson Rosenvald[5]:

"Comparando-se o art. 1831 do Código Civil de 2002 com o seu antecessor (art. 1.611, CC 1916), houve substancial acréscimo qualitativo do direito real de habitação em favor do cônjuge sobrevivente. Primeiro, o cônjuge passa a desfrutar do direito real de habitação, independente do regime de bens adotado no matrimônio - no CC de 1916, só caberia em prol do meeiro no regime da comunhão universal. Segundo, no CC de 1916 o direito de habitação era vidual, posto condicionada a sua permanência à manutenção da viuvez. Doravante, mesmo que o cônjuge sobrevivente case novamente ou inaugure união estável, não poderá ser excluído da habitação, pois tal direito se torna vitalício."

Doutra banda, parte da Doutrina, critica a postura adotada pelo legislador por entender que há uma sobreposição de direitos, onde os demais herdeiros saem prejudicados, uma vez que enquanto a viúva sobreviver tal bem não poderá ser alienado. Esta crítica foi muito bem delineada pelo llustre Jurista Caio Mário[6]:

"pois que assegura ao cônjuge supérstite (viúvo ou viúva) um direito que grava imóvel partilhado com herdeiros, sem atender aos interesses destes, além de impor inevitável desvalorização ao prédio, pois ninguém se abalançaria a adquiri-lo onerado de tal gravame. Demais disso, não se atentou para as condições econômicas do sobrevivo, que pode ter recebido em partilha enorme acervo mobiliário". 
Não obstante às criticas recebidas, tem-se que diante da supressão da expressão "enquanto viver ou permanecer viúvo" do texto legislativo, o direito real de habitação pelo cônjuge supérstite perdurará enquanto este sobreviver, independente de constituir nova família e/ou de suas condições financeiras, vez que se trata de privilégio concedido pelo legislador que desejou manter o "status" e a condição de vida do sobrevivente.

\section{A ULTRATIVIDADE DA LEI E O DIREITO REAL DE HABITAÇÃO}

Pontua-se, brevemente, que a ultratividade consiste na aplicação de lei ou dispositivo de lei já revogada a situações ocorridas durante a sua vigência. Noutras palavras, apesar da sua revogação, a lei continuará a reger algumas situações. Neste sentido, colaciona-se a preciosa lição dos professores Luciano e Roberto Figueiredo[7]:

[...] afirma-se que o CC/16 não mais possui vigência, pois ab-rogado pelo Código Civil de 2002. Entretanto, nas excepcionais hipóteses de ultratividade normativa, terá o Código Civil de 1916 vigor. É o que se dá, por exemplo, em relação à partilha de bens de alguém, realizada nos dias de hoje, mas cujo óbito fora à época do Código Civil de 1916 (CC, art. 1.787). Tal partilha seguirá a normatização do Código Civil de $1916[\ldots]$

Esta ultratividade da lei é a razão da aplicação do dispositivo previsto no art. 1611, § 2º, do Diploma Civil de 1916 (CC/1916) em determinadas situações, o que gera bastantes dúvidas e conflitos, uma vez que a alteração provocada pelo silêncio eloquente do legislador alarga o direito de um (cônjuge supérstite) em detrimento do direito de outro(s) (demais herdeiros).

Diante desta inusitada situação, quando, em análises de casos concretos, dever-se-á aplicar o Código Civil de 1916? Qual o critério utilizado para definir? 


\section{DA APLICAÇÃO DA NORMA EM CASOS CONCRETOS}

A fim de sanar qualquer dúvida acerca do tema, faz-se imperioso pontuar o critério que deve ser observado para diferenciar situações que serão regidas pelo estabelecido no Código Civil/1916 ou no Codex atual.

Nesta esteira, o marco a ser ressaltado é a data da abertura da sucessão, ou seja, a data do falecimento do autor da herança. Posto que se a sucessão fora aberta durante a vigência do Codex 1916, este deverá reger as questões inerentes ao direito sucessório, inclusive, as disposições acerca do Direito Real de Habitação.

Ainda que se questione o fato do CC/16 não mais estar em vigência, é inafastável a sua aplicação, conforme preconiza o art. 2041, do Diploma Civil em vigor[8] que em linhas gerais assevera que "As disposições deste Código relativas à ordem da vocação hereditária (arts. 1.829 a 1.844) não se aplicam à sucessão aberta antes de sua vigência, prevalecendo o disposto na lei anterior".

O Ministro Luis Felipe Salomão em julgamento de Recurso Especial decidiu de igual forma[9]: "O direito real de habitação conferido pelo Código Civil de 2002 à viúva sobrevivente, qualquer que seja o regime de bens do casamento não alcança as sucessões abertas na vigência da legislação revogada (art. 2.041 do CC/02)".

Destarte, o denominado direito real de habitação poderá ser extinto acaso o cônjuge sobrevivente contraia matrimônio ou constitua união estável superveniente a abertura da sucessão, se esta ocorreu na vigência do Código de 1916, visto que deixará de ostentar o exigido "estado de viuvez", conforme destacado no julgado proferido pelo Ilmo. Ministro Marco Aurélio Bellizze[10]: “A constituição de união estável superveniente à abertura da sucessão, ocorrida na vigência do Código Civil de 1916, afasta o estado de viuvez previsto como condição resolutiva do direito real de habitação do cônjuge supérstite".

Não obstante, se a morte do autor da herança ocorreu durante a vigência do Codex de 2002, nada impede que o cônjuge supérstite se una em matrimônio ou através de 
união estável e mantenha o exercício do direito real de habitação, visto que a exigência de mantença da viuvez fora excluída do texto legal.

A disparidade de tratamento é um dos pontos mais importantes deste estudo pois, se dê um lado denota o avanço de nossa sociedade e a devida alteração legislativa a acompanhar a evolução da forma como as pessoas se relacionam na atualidade, de outro, impõe sacrifício do direito de outrem, conforme crítica de alguns doutrinadores conforme já anotado previamente.

Por certo, assim como a expectativa em torno do Poder Legislativo exige alterações e modificações que se coadunem com os movimentos e evoluções sociais, de igual forma, espera-se que o legislador perceba os desiquilíbrios decorrentes destas modificações e crie soluções que retomem o equilíbrio dos direitos.

\section{CONCLUSÃO}

Após a avaliação dos diferentes vieses expostos por todo este artigo, resta em destaque à necessidade de se ter um legislativo atuante e conectado com a sociedade em apreço.

Afinal, o direito é uma ciência em construção, tal qual nossa sociedade. E, assim sendo, à medida que nosso cotidiano é alterado pelas novas construções sociais, nosso ordenamento é impingido a acompanhar os avanços, sob pena de restar obsoleto.

Neste sentido, como visto, o direito real de habitação sofreu as alterações decorrentes das mudanças sociais ao largo do tempo, razão pela qual se deixou de exigir a perduração do estado de viuvez para que fosse mantido o status gozado pelo cônjuge sobrevivente.

De igual forma, não restam dúvidas de que as críticas quanto a supressão da condição resolutiva são plausíveis, afinal, houve redução significativa dos direitos dos demais herdeiros, no entanto, crê-se que a lei, em constante alteração, alcançará um equilíbrio, pois, se por um lado os herdeiros podem ser prejudicados patrimonialmente 
pela ampliação das garantias conferidas ao cônjuge sobrevivente, por outro lado, não se pode engessar e proibir que este dê seguimento a sua vida sob pena de perder a segurança do lar que sempre chamou de seu.

Como se vê, o tema selecionado para o trabalho em questão é de suma importância, sendo um tema que não se restringe apenas as questões patrimoniais ou tão somente ao direito sucessório. Cuida-se de matéria que envolve disposições constitucionais, análise de regras transitórias de direito civil e áreas distintas dentro do macrorramo civilista.

Por todo o exposto, e com base nesta imensa abrangência não se pode olvidar que a discussão pode e deve se estender, sendo certo que não há qualquer pretensão de esgotamento, mas, sim, o legítimo propósito de levantar um debate acerca deste rico tema.

\section{REFERÊNCIAS}

CC/1916. Lei n. 3071/16. Diário Oficial da União.

CC/2002. Lei n. 10.406/2002. Diário Oficial da União.

de farias, Cristiano Chaves; Rosenvald, Nelson. Direitos Reais. 8. ed. Salvador: Juspodivm, 2012.

Figueiredo, Luciano ; Figueiredo, Roberto. Direito Civil Parte Geral: Sinopses para concursos. 8. ed. Salvador: Juspodivm, 2018.

gonçalves, Carlos Roberto . Direito Civil Brasileiro: Parte Geral. 15. ed. São Paulo : Saraiva, v. 1, 2017.

Pereira, Caio Mario da Silva. Instituições de Direito Civil: Direito de Família. 26. ed. Rio de Janeiro: Forense, v. 5, 2018.

STJ. Superior Tribunal de Justiça. 3ㅜㅜ. RESp n. 1.204.347/DF. Relator: Luiz Felipe Salomão. Julgamento em 02 de maio 2012. Diário Oficial da União. 
STJ. Superior Tribunal de Justiça. 3푸. RESp n. 1.617.636-DF. Relator: Marco Aurélio Bellizze. Julgamento em 27 ago. 2019. Diário Oficial da União.

\section{APÊNDICE - REFERÊNCIAS DE NOTA DE RODAPÉ}

2. Gonçalves, Carlos Roberto. Direito Civil Brasileiro: Parte Geral. 15. ed. São Paulo: Saraiva, v. 1, 2017, p. 26.

3. Artigo 1831 do CC/2002. Lei n. 10.406/2002. Diário Oficial da União.

4. Artigo 1611, §2ํㅡㄴ CC/1916. Lei n. 3.071/16. Diário Oficial da União.

5. De Farias, Cristiano Chaves; Rosenvald, Nelson. Direitos Reais. 8. ed. Salvador: Juspodivm, 2012. p. 856/857.

6. Pereira, Caio Mario da Silva. Instituições de Direito Civil: Direito de Família. 26. ed. Rio de Janeiro: Forense, v. 5, 2018. p.168/169.

7. Figueiredo, Luciano ; Figueiredo, Roberto. Direito Civil Parte Geral: Sinopses para concursos. 8. ed. Salvador: Juspodivm, 2018. p. 27/28.

8. Artigo 2041, CC/2002.

9. STJ. Superior Tribunal de Justiça. 3ํㅜ. RESp n. 1.204.347/DF. Relator: Luiz Felipe Salomão. Julgamento em 02 de maio 2012. Diário Oficial da União.

10. STJ. 3aㅡ Turma. REsp 1.617.636-DF, Rel. Min. Marco Aurélio Bellizze, julgado em 27/08/2019.

Enviado: Março, 2020.

Aprovado: Março, 2020. 